\title{
Nitrogen Tailored Activated Carbon via Microwave Synthesis Method for High Removal of Hydrogen Sulfide
}

\author{
Norhusna Mohamad Nor ${ }^{a, b}$, Lau Lee Chung ${ }^{a, c}$, Abdul Rahman Mohamed ${ }^{a, *}$ \\ a School of Chemical Engineering, Universiti Sains Malaysia, 14300 Nibong Tebal, \\ Pulau Pinang, Malaysia; ' School of Chemical Engineering, College of Engineering, \\ Universiti Teknologi MARA, Cawangan Pulau Pinang, 13500 Permatang Pauh, \\ Pulau Pinang, Malaysia; ' School of Chemical Engineering, College of Engineering, \\ Universiti Teknologi MARA, Cawangan Sarawak, Jalan Meranek, 94300 Kota \\ Samarahan, Sarawak, Malaysia.
}

Abstract In this work, commercialized palm shell activated carbon was modified into nitrogenfunctionalized carbon via urea impregnation method, followed by heat treatment via microwave irradiation at $950^{\circ} \mathrm{C}$. The efficiency of nitrogen-functionalized palm shell activated carbon $(\mathrm{N}$ PSAC) towards hydrogen sulfide $\left(\mathrm{H}_{2} \mathrm{~S}\right)$ removal was compared to raw palm shell activated carbon and sodium hydroxide impregnated palm shell activated carbon (NaOH-PSAC). These adsorbents were tested for $\mathrm{H}_{2} \mathrm{~S}$ adsorption using simulated POME biogas composition. The composition of simulated POME biogas contains $3000 \mathrm{ppm}$ of $\mathrm{H}_{2} \mathrm{~S}, 40 \%$ of $\mathrm{CO}_{2}$ and $59.7 \%$ of $\mathrm{CH}_{4}$. Experimental data showed that N-PSAC adsorbent performed better, which obtained comparable adsorption capacity $(264.3 \mathrm{mg} / \mathrm{g})$ with $\mathrm{NaOH}-\mathrm{PSAC}(240.87 \mathrm{mg} / \mathrm{g})$. The chemical and physical properties of the adsorbents were tested using elemental analysis, nitrogen adsorption desorption analysis, FTIR, and SEM analysis. Higher sorption capacity of H2S using N-PSAC showed that the introduction of basic nitrogen functionality via thermal treatment on palm shell activated carbon, significantly improved the performance of palm shell activated carbon as $\mathrm{H}_{2} \mathrm{~S}$ adsorbent.

Keywords: Hydrogen sulfide, activated carbon, biogas, nitrogen functionalized.

${ }^{*}$ For correspondence: chrahman@usm.my

Received: 8 July 2021 Accepted: 22 Nov 2021

(C) Copyright Nor et al. This article is distributed under the terms of the Creative Commons Attribution License, which permits unrestricted use and redistribution provided that the original author and source are credited.

\section{Introduction}

Palm oil industry in Malaysia has grown rapidly over the years and is accounted as one of the largest oils and fat producer in the world. Even though the industry has significantly contributed to the country's economy, increase in worldwide demand of oil palm will also worsen the environmental pollution. In 2017, about 51.19 million tonnes (Mt) of oil palm waste was generated mainly from oil palm fronds (OPF), oil palm trunks (OPT), empty fruit bunch (EFB), mesocarp fibre (MF), palm kernel shell (PKS) and palm oil mill effluent (POME) [1]. To reduce the waste generation from palm oil industry, POME has been utilized to produce biogas via anaerobic digestion process and it has been applied in some of palm oil mills in Malaysia as a feedstock for biogas production [2]. In general, biogas composition produced from POME is typically contains $50-70 \%$ of methane $\left(\mathrm{CH}_{4}\right), 30-40 \%$ of carbon dioxide $\left(\mathrm{CO}_{2}\right)$ and traces $(1000-3000 \mathrm{ppm})$ of hydrogen sulfide $(\mathrm{H} 2 \mathrm{~S})$ [2-3]. These gases have been identified as greenhouse gas $(\mathrm{GHG})$ source, which could contribute to global warming effect. The GHG potential of $\mathrm{CH} 4$ is approximately 20 times of $\mathrm{CO}_{2}$ and it would be equivalent to 7.2 million tons of $\mathrm{CO}_{2}$ emission [4]. Since $\mathrm{CH} 4$ has physical and chemical properties that is close to natural gas, it would be a great advantage to integrate $\mathrm{CH} 4$ as a renewable energy and at the same time eliminating its contribution towards global warming. However, to utilize $\mathrm{CH} 4$ as a renewable energy, traces of $\mathrm{H} 2 \mathrm{~S}$ need to be removed. 
$\mathrm{H} 2 \mathrm{~S}$ is an extremely toxic and hazardous gas with unpleasant smell. The presence of $\mathrm{H} 2 \mathrm{~S}$ in biogas could cause corrosion to the gas engine and metal parts via emission of sulfur dioxide (SO2) during combustion, especially when the gas engine is not operated continuously. Apart from that, $\mathrm{H} 2 \mathrm{~S}$ and $\mathrm{SO} 2$ concentrations emitted to the workplace would be toxic for workers as well [5]. This has been reported that, even at a very low concentration of $\mathrm{H} 2 \mathrm{~S}(5 \mathrm{ppm})$ it is still hazardous to human health [6]. To cater this problem, there are various technologies that are available to remove traces of $\mathrm{H} 2 \mathrm{~S}$ from biogas, such as absorption, adsorption on a solid material (such as iron oxide-based materials or activated carbon), and biological conversion [5-6]. Among these technologies, adsorption on activated carbon/impregnated activated carbon has been widely used due to its effectiveness in removing gaseous pollutant [5].

Activated carbon is a low-cost adsorbent where it could be easily modified to obtain good surface properties that is capable for high adsorption capacity and fast reaction kinetic. The use of lignocellulosic biomass to be converted into activated carbon precursor is relatively economic and easy because it is abundantly available. The utilization of palm shell biomass into activated carbon adsorbent for $\mathrm{H} 2 \mathrm{~S}$ removal in this study could establish a 'carbon neutral cycle', since both are by-products produced from palm oil industries [7]. The adsorption capacity of modified activated carbon will depend on the type of chemicals used, due to the changes of surface chemistry and physical characteristics. Previous researchers reported, to enhance the adsorption capacity of $\mathrm{H} 2 \mathrm{~S}$, the activated carbons need to be modified via chemical activation, which promotes high oxidation of $\mathrm{H} 2 \mathrm{~S}$ to elemental sulfur [8-10]. This includes introducing oxidative agent via impregnation method $(\mathrm{KOH}, \mathrm{NaOH}, \mathrm{NaCO}, \mathrm{KI}, \mathrm{KMnO} 4)$ and alteration of surface chemistry of the carbon matrix and incorporation of heteroatom such as nitrogen functionality (urea, melamine, NH3). The introduction of nitrogen onto activated carbon surface could enhance the adsorption of H2S. The existence of nitrogen on activated carbon surface can increase the basic groups, thus the oxidation of acidic gas such as H2S into sulfur can occurred easily [11-13].

The objective of this paper is to study the effect of nitrogen enhanced adsorbent by using urea as a source of nitrogen onto palm shell activated carbon (PSAC). The synthesis method will be done via microwave (MIW) irradiation heating method. Previously, researchers have conducted study related to the effect of nitrogen functionality on adsorption of $\mathrm{H} 2 \mathrm{~S}$ by using various type of waste materials [11-13]. Up to date, nitrogen-modified activated carbon has been produced via conventional heating method by using external heat source which are very slow and inefficient, due to the transfer of energy into the system. However, in this study MW heating method will be introduced, where it could offer efficient heating mechanism since it requires short reaction time. Moreover, activated carbon that undergo MW heating is a great absorbers of MW energy and it could convert the energy easily into heat [14-16]. This study is conducted for the purpose of improving the physicochemical properties of PSAC. For this purpose, the best selected synthesis parameter from previous research work [11] have been followed to study the effect of nitrogen functionality on the PSAC. Raw PSAC and $\mathrm{NaOH}$ impregnated PSAC (NAOHPSAC) were used to compare the adsorption capacity of H2S.

\section{Materials and Methods}

\section{Materials}

A commercial palm shell based activated carbon (KD Carbon Sdn. Bhd., Malaysia) was used in this study. The raw sample is designated as PSAC. In the $\mathrm{NaOH}$ impregnation step, $\mathrm{NaOH}$ pellet (Merck, $\geq 97.0 \%$ ) was used. In the urea impregnation step, nitric acid $\left(\mathrm{HNO}_{3}\right)$ (Merck, 65\%), urea (Merck, 99\%), ethanol (Merck, $96 \%$ ) and purified nitrogen $\left(\mathrm{N}_{2}\right)$ gas $\left(99.99 \% \mathrm{~N}_{2}\right)$ used for purging was supplied by Linde (M) Sdn Bhd. In the $\mathrm{H}_{2} \mathrm{~S}$ adsorption test, $99.99 \% \mathrm{~N}_{2}$ and $1 \% \mathrm{H}_{2} \mathrm{~S}$ in $\mathrm{N}_{2}$ supplied by Linde (M) Sdn. Bhd. were used. The modified PSAC samples were referred as NaoH-PSAC and N-PSAC, in which both were impregnated using $\mathrm{NaOH}$ and urea, respectively.

\section{PSAC Impregnation}

NAOH-PSAC. The sample was prepared by mixing $100 \mathrm{~mL}$ of $1 \mathrm{wt} \% \mathrm{NaOH}$ solution with $5 \mathrm{~g}$ of raw PSAC. The solution was stirred at $180 \mathrm{rpm}, 25^{\circ} \mathrm{C}$ for $3 \mathrm{~h}$. Then, the mixture was heated at $100^{\circ} \mathrm{C}$ with constant stirring until all liquid evaporated. The $\mathrm{NaOH}-\mathrm{PSAC}$ was then dried in an oven at $120^{\circ} \mathrm{C}$ for $6 \mathrm{~h}$ [9].

N-PSAC. PSAC was pre-oxidized using $250 \mathrm{~mL}$ of $50 \mathrm{wt} \% \mathrm{HNO}_{3}$ for $4 \mathrm{~h}$. Then, it was rinsed with distilled water to remove excess acid and oxidized water-soluble products prior to nitrogen functionalization. Nitrogen species was introduced to the pre-oxidized PSAC via urea impregnation. The solution containing urea $(20 \mathrm{~g})$, oxidized carbon $(30 \mathrm{~g})$ and ethanol $(100 \mathrm{~mL})$ was stirred $(180 \mathrm{rpm})$ at room 
temperature for $5 \mathrm{~h}$. Then, the mixture was boiled to evaporate the alcohol, before continuing with the drying of the impregnated sample at $110^{\circ} \mathrm{C}$ [11]. The impregnated sample was then heated using MW under $500 \mathrm{ml} / \mathrm{min}$ of $\mathrm{N}_{2}$ flow at $950{ }^{\circ} \mathrm{C}$ for $0.5 \mathrm{~h}$. The $\mathrm{N}-\mathrm{PSAC}$ was washed with boiling water to remove excess of urea product and was dried in an oven at $120^{\circ} \mathrm{C}$ for $6 \mathrm{~h}$.

\section{$\mathrm{H}_{2} \mathrm{~S}$ Adsorption Study}

A custom designed $\mathrm{H}_{2} \mathrm{~S}$ scrubber rig was used to test the performance of the adsorbent samples prepared. A $1.0 \mathrm{~g}$ of the adsorbent samples (size: $0.5-1 \mathrm{~mm}$ ) was weighed and placed in the middle of stainless-steel column (length $450 \mathrm{~mm}$, internal diameter $12.5 \mathrm{~mm}$ ), supported with approximately $0.5 \mathrm{~g}$ of borosilicate glass wool. In this work, a simulated biogas mixture containing $59.7 \%$ of $\mathrm{CH}_{4}, 40 \%$ of $\mathrm{CO}_{2}$ and $3000 \mathrm{ppm}$ of $\mathrm{H}_{2} \mathrm{~S}$ was passed through the column under a fixed flow rate of $300 \mathrm{ml} / \mathrm{min}$. The biogas composition used was simulated to mimic the actual composition of digestion pond located in Felda Besout Palm Oill Mill, Malaysia. The simulated biogas composition was adjusted by controlling the gas flow rate by using Aalborg AFC26 mass flow controllers. To achieve $25 \%$ of biogas relative humidity, $\mathrm{CH}_{4}$ and $\mathrm{CO}_{2}$ were passed through the humidification system first before entering the column. $\mathrm{H}_{2} \mathrm{~S}$ was not passed through the humidification system due to it is soluble in water [10]. The outlet concentration of $\mathrm{H}_{2} \mathrm{~S}$ was monitored by using a continuous biogas analyzer (IMR500) via electrochemical sensor calibrated for $0-5000 \mathrm{ppm}$ of $\mathrm{H}_{2} \mathrm{~S}$ range. To ensure the safety of the workstation, the ventilation system of the rig was installed in case there is a leakage of hazardous $\mathrm{H}_{2} \mathrm{~S}$ gas.

\section{pH of the Carbon Surface}

The value of acidity/basicity of the adsorbent samples were tested. Each of $0.4 \mathrm{~g}$ of dry adsorbent sample was added to $20 \mathrm{~mL}$ of distilled water and the suspension was stirred overnight to reach equilibrium. Then, the sample was filtered, and the $\mathrm{pH}$ of the solution was measured by using $\mathrm{pH}$ meter (Eutech Instruments $\mathrm{pH} 700$ ).

\section{CHNS/O Analysis}

The elemental analysis was performed using a Perkin Elmer $2400 \mathrm{CHNS}$ Analyzer to analyze the content of carbon, hydrogen, nitrogen, sulfur and oxygen in the sample.

\section{$\mathrm{N}_{2}$ Adsorption/Desorption}

Nitrogen adsorption/desorption was carried out using Micromeritics ASAP 2020 surface area and porosity analyzer. Before the experiment, the samples were heated at $120^{\circ} \mathrm{C}$ and degassed to constant vacuum $\left(10^{-4} \mathrm{kPa}\right)$ for 5 hours. Nitrogen isotherms were used to calculate the specific surface area $\left(\mathrm{S}_{\mathrm{BET}}\right)$, micropore volume $\left(\mathrm{V}_{\text {mic }}\right)$, and total pore volume $\left(\mathrm{V}_{\mathrm{t}}\right)$.

\section{FESEM}

The analysis of Field-emission Scanning Electron Microscopy (FESEM) was carried out using Quanta FEG 450 at accelerating voltage of $3 \mathrm{kV}$, to obtain the sorbent surface morphologies.

\section{FTIR}

Surface functional groups of the samples were analyzed using Fourier-transform infrared spectroscopy (FTIR). The analysis was carried out using Nicolet 6700 and the adsorbents samples were analyzed in the range of $400-4000 \mathrm{~cm}^{-1}$ spectrum.

\section{Results and Discussion}

\section{$\mathrm{H}_{2} \mathrm{~S}$ Adsorption}

In this study, palm shell activated carbon that undergoes nitrogen modification (N-PSAC) was compared with raw palm shell activated carbon (PSAC) and $\mathrm{NaOH}$ impregnation palm shell activated carbon (PSAC-N). The performance of each carbon sample was analyzed using $\mathrm{H}_{2} \mathrm{~S}$ breakthrough curve, $\mathrm{H}_{2} \mathrm{~S}$ adsorption capacity, and the length of mass transfer zone ( $\left.\mathrm{L}_{M T Z}\right)$. Figure 1 shows the $\mathrm{H}_{2} \mathrm{~S}$ breakthrough curve for PSAC, NAOH-PSAC and N-PSAC adsorbents, which emphasized on the fixed bed adsorption type. It was observed that the breakthrough curve for both $\mathrm{NaOH}-\mathrm{PSAC}$ and N-PSAC showed a longer trend compared to PSAC. 


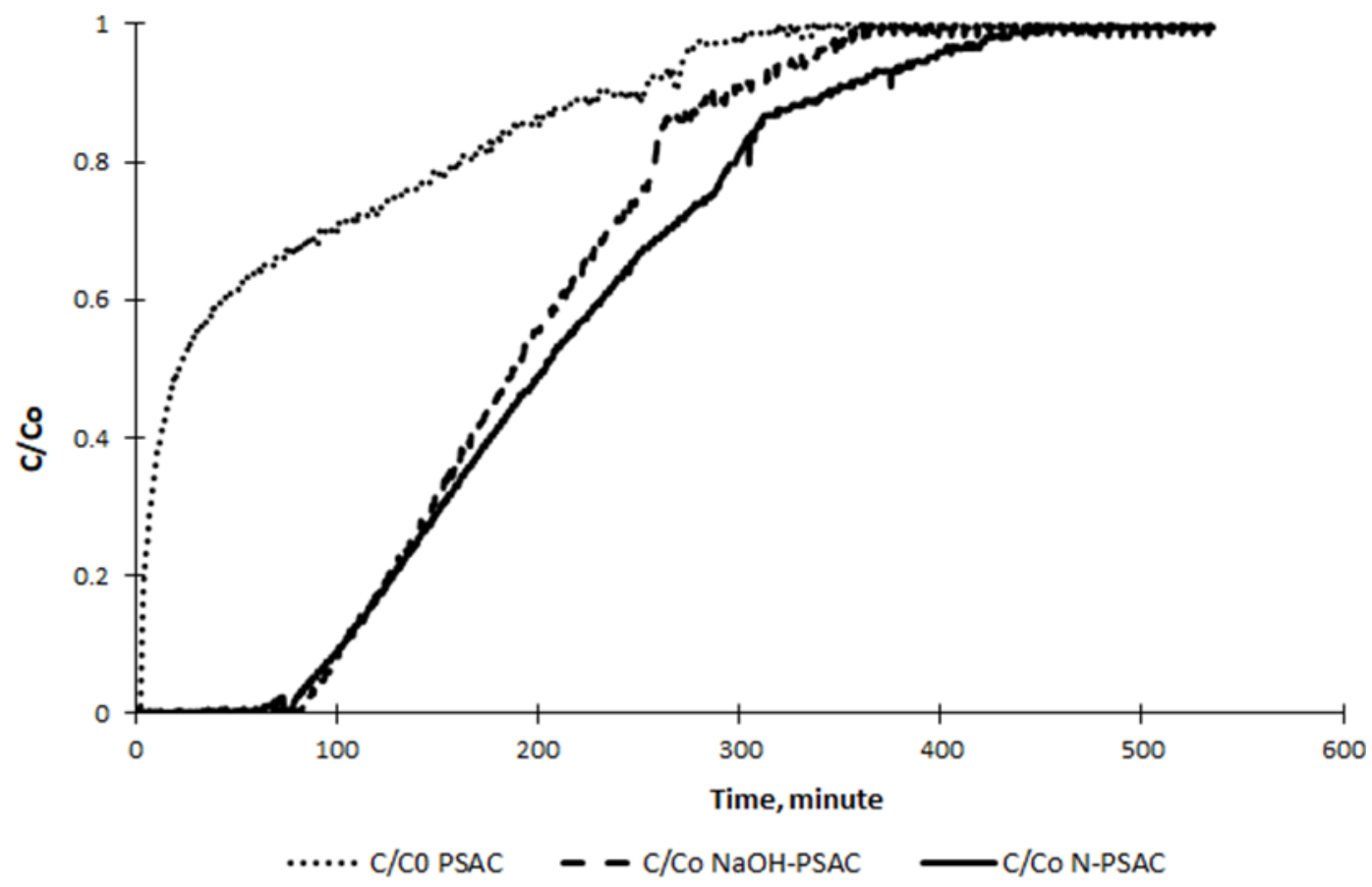

Figure 1. Breakthrough curve for raw and modified palm shell activated carbons.

Based on the breakthrough curve, the adsorption capacity for each carbon sample was calculated, where the breakthrough capacity was calculated at breakthrough time (where $\mathrm{C} / \mathrm{Co}=0.05$ ) and the total adsorption capacity was calculated after the adsorbent reach equilibrium or saturated (where $\mathrm{C} / \mathrm{Co}=$ 0.95). The $\mathrm{H}_{2} \mathrm{~S}$ breakthrough-curve and characteristics of all adsorbent samples are tabulated in Table 1. As expected, for NAOH-PSAC and N-PSAC, a significant increase in the adsorption capacity was found compared to PSAC. The highest $\mathrm{H}_{2} \mathrm{~S}$ breakthrough capacity was obtained using NAOH-PSAC followed by N-PSAC. However, the total $\mathrm{H}_{2} \mathrm{~S}$ adsorption capacity exhibited a reversed outcome, where the N-PSAC was capable to adsorb more $\mathrm{H}_{2} \mathrm{~S}$ with the total adsorption capacity of $264.29 \mathrm{mg} / \mathrm{g}$, which is slightly higher than the NAOH-PSAC $(240.87 \mathrm{mg} / \mathrm{g})$.

The length of mass transfer zone $\left(L_{M T Z}\right)$ has been studied to find out the active part of the bed where the adsorption is actually takes place. Mass transfer zone (MTZ) is the part in breakthrough curves that display a gradient in adsorbent concentration from zero to equilibrium. As the saturated part of the bed increases, the MTZ travels downstream and eventually exits the bed. The $L_{M T Z}$ is calculated as in equation (1) [17]:

$$
L_{M T Z}=\frac{L\left(t_{0.05}-t_{0.95}\right)}{\left(t_{0.05}+t_{0.95}\right) / 2}
$$

Where $L$ is length of fix bed $(\mathrm{cm}), t_{0.05}$ is breakthrough time at $C / C_{0}=0.05(s)$, and $t_{0.95}$ is saturated time at $\mathrm{C} / \mathrm{C}_{0}=0.95(\mathrm{~s})$.

Table 1. $\mathrm{H}_{2} \mathrm{~S}$ breakthrough-curve and characteristics of raw and modified PSAC adsorbents.

\begin{tabular}{|c|c|c|c|c|c|}
\hline $\begin{array}{l}\text { Activated } \\
\text { carbon }\end{array}$ & $\begin{array}{l}\text { Breakthrough } \\
\text { time, } t_{0.05}(\mathrm{~min})\end{array}$ & $\begin{array}{c}\text { Saturated } \\
\text { time, } t_{0.95} \\
\quad(\min )\end{array}$ & $\begin{array}{c}\mathrm{H}_{2} \mathrm{~S} \\
\text { breakthrough } \\
\text { capacity } \\
(\mathrm{mg} / \mathrm{g})\end{array}$ & $\begin{array}{c}\text { Total } \mathrm{H}_{2} \mathrm{~S} \\
\text { adsorption } \\
\text { capacity }(\mathrm{mg} / \mathrm{g})\end{array}$ & $\begin{array}{l}\text { Length of } \\
\text { MTZ, L } \text { LTZ } \\
\quad(\mathrm{cm})\end{array}$ \\
\hline PSAC & 5.0 & 312.0 & 6.16 & 91.28 & 0.97 \\
\hline $\begin{array}{l}\mathrm{NAOH}- \\
\mathrm{PSAC}\end{array}$ & 93.5 & 388.0 & 115.27 & 240.87 & 0.61 \\
\hline N-PSAC & 87.0 & 423.5 & 107.25 & 264.29 & 0.66 \\
\hline
\end{tabular}

From Table 1, NAOH-PSAC shows better dynamic adsorption performances due to longer breakthrough 
time, prolonged saturated time, and relatively shorter $\mathrm{L}_{\mathrm{MTZ}}$ [9] compared to the PSAC and N-PSAC. Thus, this results in higher adsorption capacity. Competitively, N-PSAC also developed a very short $L_{M T Z}(0.66$ $\mathrm{cm}$ ) where it took a little bit longer than the $L_{M T Z}$ of NAOH-PSAC $(0.61 \mathrm{~cm})$. This explains the difference in $\mathrm{H}_{2} \mathrm{~S}$ breakthrough capacity for both NAOH-PSAC and N-PSAC. Again, both the $\mathrm{L}_{\mathrm{MTZ}}$ and adsorption capacities show that the N-PSAC is comparable to NAOH-PSAC. To understand better, details characteristics study was done in this work, to identify the factors that influence the $\mathrm{H}_{2} \mathrm{~S}$ adsorption by using these adsorbent samples.

\section{$\mathrm{N}_{2}$ Adsorption Desorption}

Even though N-PSAC and NAOH-PSAC could adsorb $\mathrm{H}_{2} \mathrm{~S}$ very well compared to PSAC, the surface characteristics shown in Table 2 for these two adsorbent samples give divergence results. Increase of $\mathrm{pH}$ and surface area was found in $\mathrm{NAOH}-\mathrm{PSAC}$ while decrease of $\mathrm{pH}$ and surface area was found in $\mathrm{N}$ PSAC. As for NAOH-PSAC, with strong basic surface $(\mathrm{pH} 9.43)$ due to the presence of $\mathrm{NaOH}$ could easily enhance the oxidation of acidic $\mathrm{H}_{2} \mathrm{~S}$ to sulfur [10]. Under this circumstance, existing chemical reaction between $\mathrm{H}_{2} \mathrm{~S}$ and $\mathrm{NaOH}$ results in high adsorption capacity of $\mathrm{H}_{2} \mathrm{~S}$, where the breakthrough capacity per unit pore volume calculated was $217.49 \mathrm{mg} / \mathrm{cm}^{3}$. Higher in surface area of NAOH-PSAC also provides better space to store $\mathrm{H}_{2} \mathrm{~S}$, thus enhance the $\mathrm{H}_{2} \mathrm{~S}$ adsorption capacity. As reported in Adib et al. [18], the $\mathrm{pH}$ value for nitrogen-modified activated carbon is typically within $\mathrm{pH} 6-8$. In this study, the $\mathrm{pH}$ value obtained for N-PSAC is $\mathrm{pH} 7.02$, where N-PSAC's condition is less basic compared to $\mathrm{NAOH}-\mathrm{PSAC}$. However, the $\mathrm{pH}$ value for N-PSAC is still in agreeable range. The existence of basicity factor in N-PSAC, altogether with other factors such as surface area and pore volume offers a great help for oxidation of $\mathrm{H}_{2} \mathrm{~S}$ to happen.

Table 2. Physical and surface properties of raw and modified palm shell activated carbons.

\begin{tabular}{|c|c|c|c|c|c|c|c|}
\hline Sample & $\begin{array}{c}\mathrm{pH} \\
27^{\circ} \mathrm{C}\end{array}$ & $\begin{array}{c}\text { Surface } \\
\text { area, } \\
\mathrm{S}_{\mathrm{BET}} \\
\left(\mathrm{m}^{2} / \mathrm{g}\right)\end{array}$ & $\begin{array}{c}\text { Micropore } \\
\text { volume, } \\
V_{\text {mic }} \\
\left(\mathrm{cm}^{3} / \mathrm{g}\right)\end{array}$ & $\begin{array}{c}\text { Total } \\
\text { pore } \\
\text { volume, } \\
V_{\mathrm{t}} \\
\left(\mathrm{cm}^{3} / \mathrm{g}\right)\end{array}$ & $\begin{array}{l}\text { Micropore } \\
\text { surface } \\
\text { area, } \mathrm{S}_{\text {mic }} \\
\left(\mathrm{m}^{2} / \mathrm{g}\right)\end{array}$ & $\begin{array}{c}\text { Total } \\
\text { surface } \\
\text { area, } \mathrm{S}_{\mathrm{t}} \\
\left(\mathrm{m}^{2} / \mathrm{g}\right)\end{array}$ & $\begin{array}{c}\text { Breakthrough } \\
\text { capacity per } \\
\text { unit pore } \\
\text { volume } \\
\left(\mathrm{mg} / \mathrm{cm}^{3}\right)\end{array}$ \\
\hline PSAC & 8.48 & 947.32 & 0.40 & 0.51 & 827.84 & 957.00 & 12.07 \\
\hline NAOH-PSAC & 9.43 & 1085.97 & 0.39 & 0.53 & 798.90 & 1107.55 & 217.49 \\
\hline N-PSAC & 7.02 & 886.75 & 0.30 & 0.47 & 611.27 & 896.30 & 228.19 \\
\hline
\end{tabular}

As suggested by Bagreev and Bandosz, high $\mathrm{H}_{2} \mathrm{~S}$ adsorption of $\mathrm{NAOH}-\mathrm{PSAC}$ is basically caused by higher surface area, the effect of surface functional group, and the effect of chemical reaction [19]. Even though the surface properties of N-PSAC shown opposite results compared to NAOH-PSAC, the adsorption capacity of N-PSAC is comparable to NAOH-PSAC (an established good alkaline impregnation agent). The reason is due to the changes of porosity, especially small micropore size (Figure 2) and surface chemistry of N-PSAC via introduction of nitrogen functionality on N-PSAC. From Table 2, it is clearly seen that after undergoes thermal treatment via $\mathrm{MW}$ at $950^{\circ} \mathrm{C}$, there is some reduction in the physical and surface characteristic of N-PSAC compared to PSAC. This trend agrees with previous studies where the impregnation of urea had been done via conventional thermal treatment [20]. A clearer view of pore sizes and their contribution to porosity has been illustrated in Figure 2, where the pore width for PSAC is in the range of $30-40 \AA$ and the pore width for both N-PSAC and NAOHPSAC are in the range of $10-30 \AA$.

Seredych et al. [20] indicated that adsorbent samples that have small micropores are more effective. Smaller pores could immobilize $\mathrm{H}_{2} \mathrm{~S}$ gas inside the pores whilst avoiding the gas from escaping out of the adsorbent sample, given more binding time for $\mathrm{H}_{2} \mathrm{~S}$ to react with available functional groups. $\mathrm{H}_{2} \mathrm{~S}$ is a small molecule, thus small pores are more favorable for its physical adsorption due to increase the adsorption potential via trapping the gas molecule into small pores. Thus, compared to PSAC, shrinkage of pores width in the N-PSAC provides better structure where it could trap and adsorbs $\mathrm{more}_{2} \mathrm{~S}$ molecules. Adib et al. [18] reported that thermal treatment at high temperature $\left(950{ }^{\circ} \mathrm{C}\right)$ causes the carbon grains to shrink $30 \%$ of original size because of the increase in the adsorption energy characteristics. Thus, this explains why the surface area of N-PSAC is decreased by $10 \%$ compared to the PSAC. The shrinkage of carbon grains also affected the N-PSAC's pore width, where it decreases significantly. In this study, the breakthrough adsorption capacity has been divided by total pore volume, to calculate the normalized capacity, as shown in Table 2. The results show that the N-PSAC has higher normalized capacity followed by NAOH-PSAC and PSAC. This might be the reason why the total adsorption capacity of NAOH-PSAC is slightly lower than N-PSAC (Table 1). 


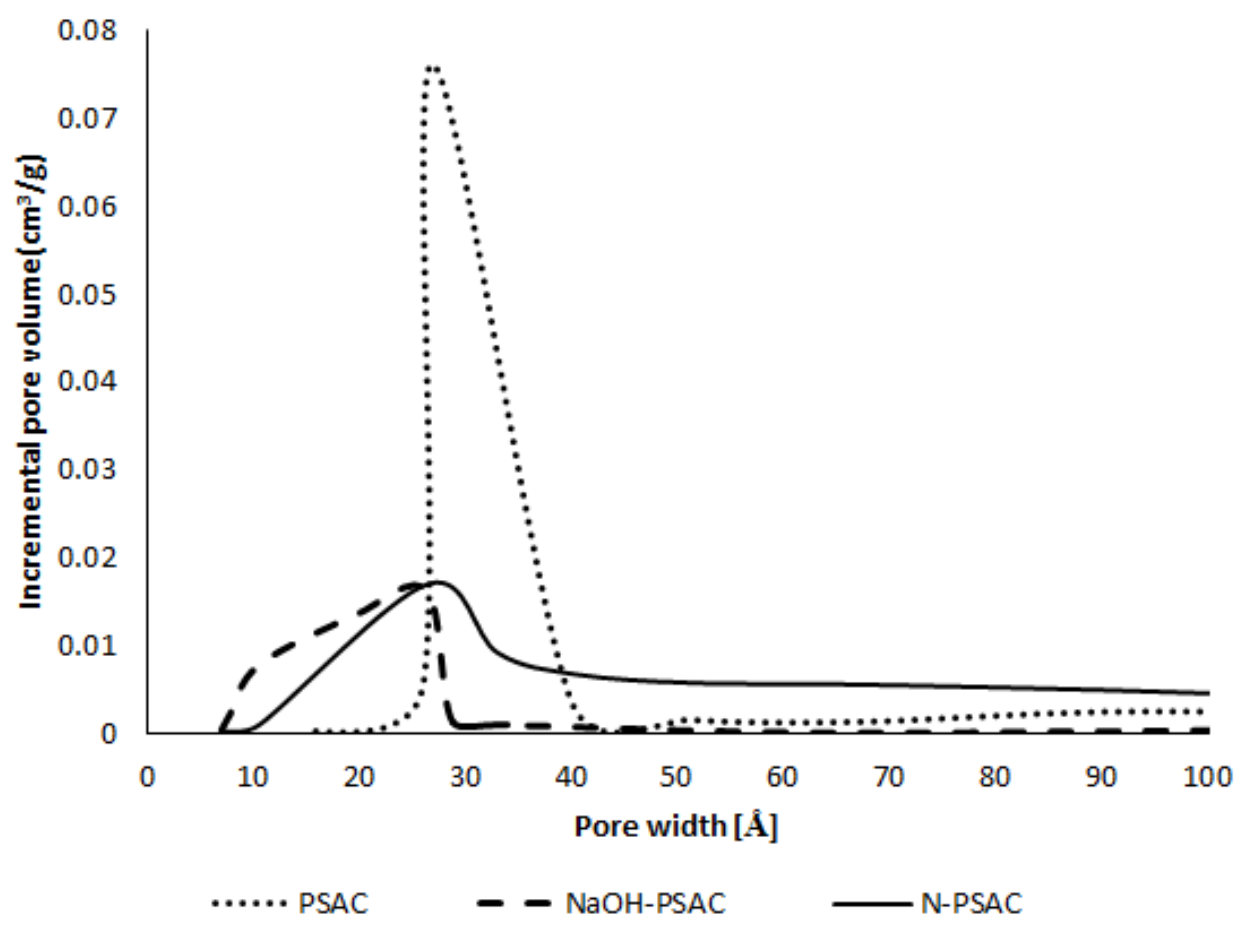

Figure 2. Pore size distribution (DFT) FTIR spectrum of PSAC, NaOH-PSAC, N-PSAC

\section{Surface Functional Groups and Elemental Analysis}

Figure 3 illustrates the FTIR spectra for all adsorbent samples. The PSAC spectrum show significant bands at $800-1600 \mathrm{~cm}^{-1}$ (C-H bond, C-O-C functional groups), $2800-3200 \mathrm{~cm}^{-1}$ (-COOH functional groups), and $3600-4000 \mathrm{~cm}^{-1}$ (O-H stretching vibration) wavelengths [21]. The bands of the N-PSAC were observed at $1200 \mathrm{~cm}^{-1}\left(\mathrm{C}-\mathrm{N}\right.$ stretching vibration), $1400-1600 \mathrm{~cm}^{-1}(\mathrm{C}-\mathrm{N}-$ vibrations in secondary aromatic amines and $\mathrm{N}=\mathrm{N}$ arrangement), and $3600-4000 \mathrm{~cm}^{-1}(\mathrm{O}-\mathrm{H}$ or $\mathrm{N}-\mathrm{H}$ stretching vibration). The modification of N-PSAC removed some surface oxygen-containing groups and resulted in the incorporation of nitrogen to the carbon structure. As for the $\mathrm{NaOH}-\mathrm{PSAC}$, some functional groups were removed, and new bands were identified. The new bands are observed at $1200-1400 \mathrm{~cm}^{-1}(C=O$, carbonyl compound), $2800-3000$ and $3600-4000 \mathrm{~cm}^{-1}(\mathrm{O}-\mathrm{H}$ stretching bond). This confirmed the presence of a large amount of $\mathrm{O}-\mathrm{H}$ functional groups on the surface of $\mathrm{NaOH}-\mathrm{PSAC}$, which resulted in high adsorption of $\mathrm{H}_{2} \mathrm{~S}$. According to Wang et al., the active $-\mathrm{OH}$ functional groups produced by the $\mathrm{NaOH}$ impregnation played a substantial role in increasing the adsorption performance of $\mathrm{H}_{2} \mathrm{~S}$ [9]. Therefore, this can be concluded that the performance of these adsorbent samples can be related with the functional groups that were crafted on the surface of the adsorbents.

The discussion of functional groups can be supported with the elemental analysis presented in Table 3. From the table, a significant amount of nitrogen was found in the N-PSAC. The existence of nitrogen element in N-PSAC is due to most of nitrogen elements are easily incorporated into the carbon matrix as a component of aromatic ring at high temperature [11]. This finding is supported by Adib et al. [18], where the adsorption capacity of $\mathrm{H}_{2} \mathrm{~S}$ for adsorbent sample that undergo low temperature $\left(450{ }^{\circ} \mathrm{C}\right)$ was not comparable to the adsorption capacity of $\mathrm{H}_{2} \mathrm{~S}$ for adsorbent sample that undergo high temperature $\left(950^{\circ} \mathrm{C}\right)$ treatment. Hence, the use of $950^{\circ} \mathrm{C}$ treatment for $\mathrm{N}-\mathrm{PSAC}$ helps in binding the nitrogen element in the carbon matrix. Apart from the effect of high temperature treatment, the PSAC's high surface area $\left(947.32 \mathrm{~m}^{2} / \mathrm{g}\right)$ is also one of the factors that contribute to the accessibility of nitrogen to be incorporated into the crystallite edges. This increased the carbon content accompanied by the decrease in hydrogen content for the N-PSAC compared to the PSAC. The changed in the elemental composition happened due to the degree of carbonization itself that has been changed, since it undergoes high temperature treatment twice (the first one is before impregnation). The existence of nitrogen functionality in the $\mathrm{N}$ PSAC assists in the oxidation of $\mathrm{H}_{2} \mathrm{~S}$ where the chemical reaction will take place during the immobilization of $\mathrm{H}_{2} \mathrm{~S}$ because of its smaller pores. This circumstance justifies the higher value of total adsorption capacity of N-PSAC compared to NAOH-PSAC. Apart from that, in the $\mathrm{NaOH}-\mathrm{PSAC}$ a significant oxygen composition was observed, which supported the finding from FTIR's spectrum discussed earlier. 

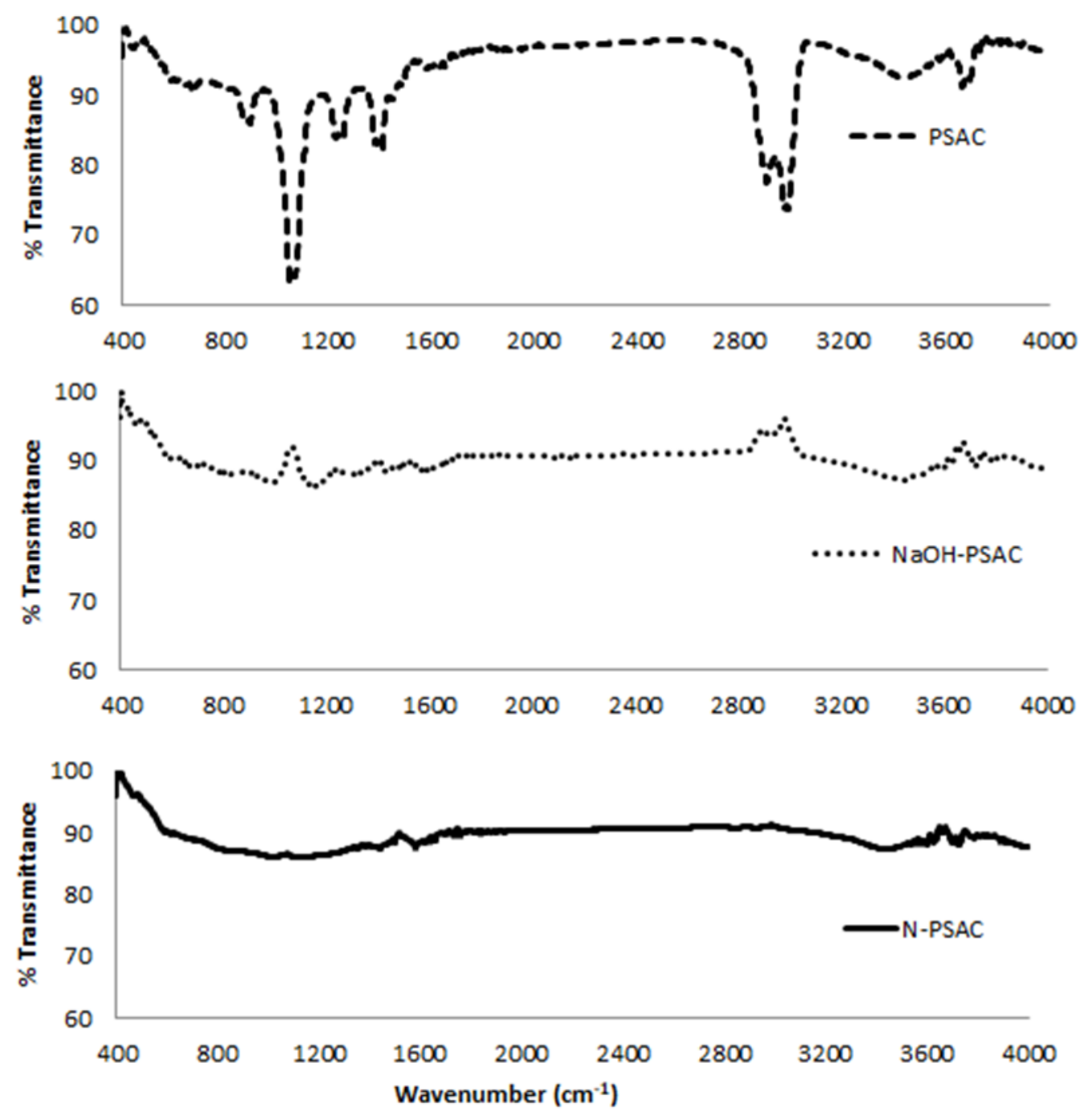

Figure 3. FTIR spectrum of PSAC, NaOH-PSAC, N-PSAC

Table 3. Elemental analysis of raw and modified PSAC adsorbents (before and after $\mathrm{H}_{2} \mathrm{~S}$ adsorption)

\begin{tabular}{lccccc}
\hline Element & $\% \mathrm{C}$ & $\% \mathrm{H}$ & $\% \mathrm{~N}$ & $\% \mathrm{~S}$ & $\mathrm{O} \%$ \\
\hline PSAC & 61.61 & 1.48 & - & - & 36.99 \\
Spent PSAC & 62.27 & 0.59 & - & 6.47 & 30.67 \\
NAOH-PSAC & 59.98 & 0.45 & - & - & 39.57 \\
Spent NAOH-PSAC & 62.44 & 0.14 & - & 9.39 & 28.03 \\
N-PSAC & 79.92 & 0.90 & 0.49 & - & 18.69 \\
Spent N-PSAC & 61.71 & 0.76 & 0.32 & 13.49 & 23.72 \\
\hline
\end{tabular}




\section{Surface Morphologies}

Figure 4 shows the images of before and after $\mathrm{H}_{2} \mathrm{~S}$ adsorption of all adsorbent samples that were characterized using FESEM analysis at magnification of 5000X. The elemental sulfur was detected by the EDX analysis that is illustrated in Figure 5. It can be clearly seen that the elemental sulfur has been deposited on the surface of all spent adsorbent samples in Figure 5. From the images, as for the PSAC, the micropores seem has been clogged by char and were not well developed, thus this resulted in low adsorption capacity of $\mathrm{H}_{2} \mathrm{~S}$. On the other hand, for both NAOH-PSAC and N-PSAC, the surfaces of the adsorbent samples were showing the existence of $\mathrm{NaOH}$ and urea respectively as detected by EDX analysis. Thus, this suggests that both of NAOH-PSAC and N-PSAC undergo chemical adsorption during $\mathrm{H}_{2} \mathrm{~S}$ adsorption process. Based on the FESEM images, conventional thermal method (PSAC) and MW irradiation heating method (N-PSAC) have an identical effect onto the inner structure and the morphology of active carbon. However, by using MW heating method could change drastically the amorphous active carbon, where the cavities were intensified, and the inner surface of the sample are significant. In this study, N-PSAC developed a good amorphous active site where it formed narrow pores size since the broken carbon surface had a minimal expansion. Thus, this indicated that the production of N-PSAC via MW irradiation method could enhance the adsorption of $\mathrm{H}_{2} \mathrm{~S}$, and the results will be greater if certain parameters such as MW temperature, flow rate of nitrogen gas, and holding time during MW heating method were optimized.
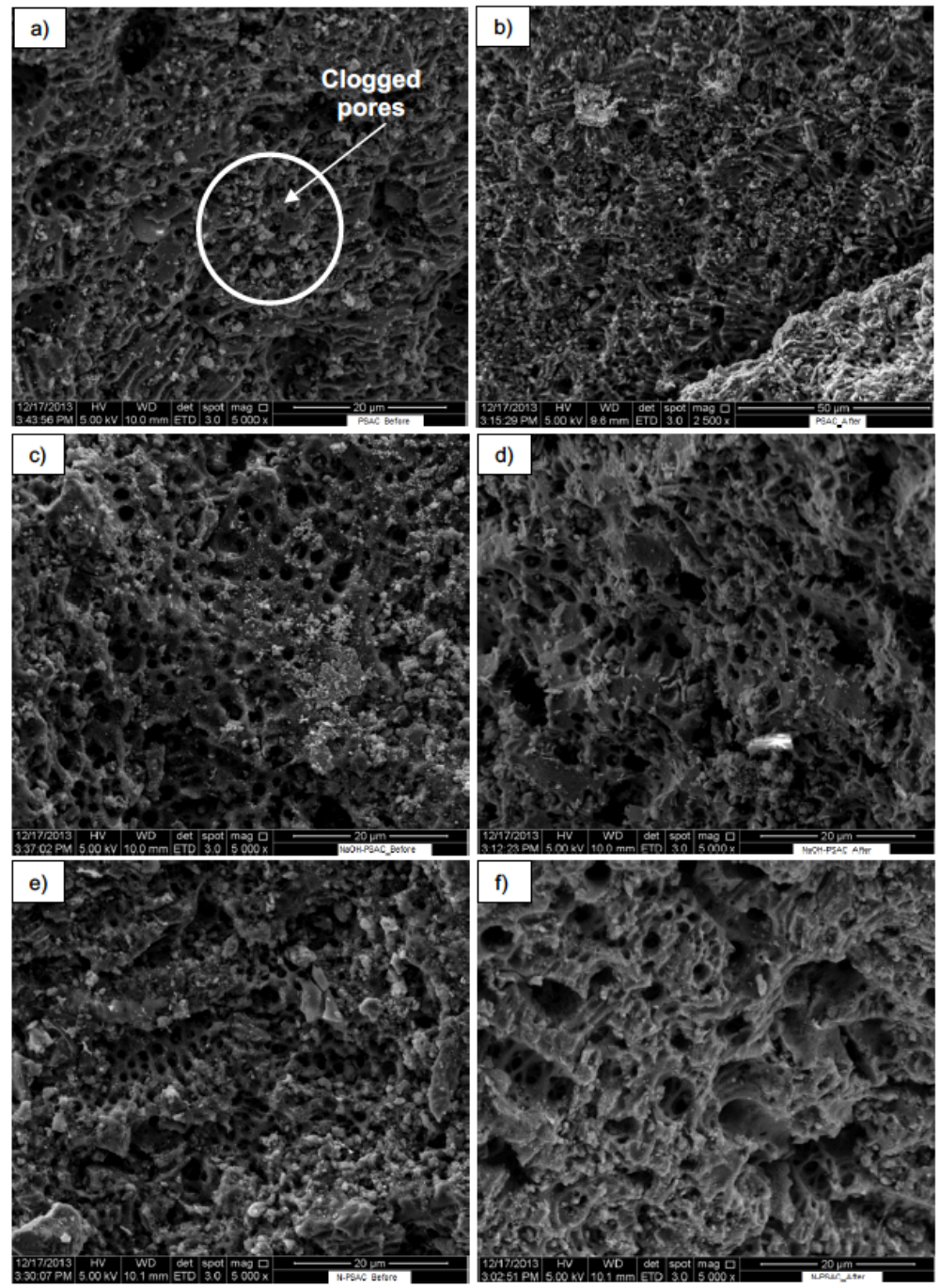

Figure 4. FESEM images of raw and modified palm shell activated carbons before and after $\mathrm{H}_{2} \mathrm{~S}$ adsorption at magnification of 50nx: a) PSAC_before, b) PSAC_after, c) NaOH-PSAC_before, d) NAOH-PSAC_after, e) N-PSAC_before, ánd f) N-PSAC_after 

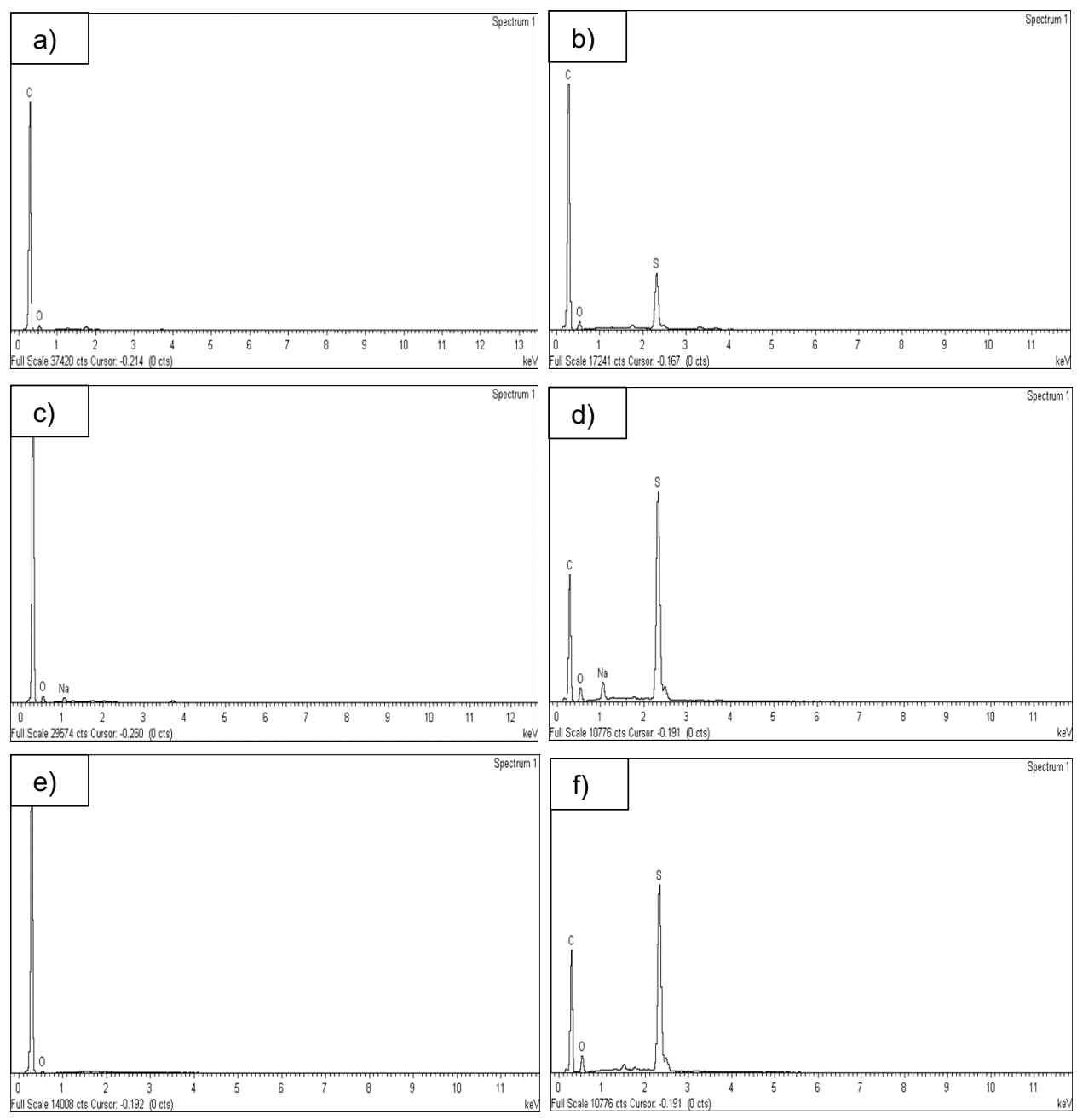

Figure 5. EDX spectrum of raw raw and modified palm shell activated carbons before and after $\mathrm{H}_{2} \mathrm{~S}$ adsorption at magnification of 5000x; a) PSAC_before, b) PSAC_after, c) NaOH-PSAC_before, d) NAOH-PSAC_after, e) N-PSAC_before, and f) N-PSAC_after.

\section{Conclusions}

The results presented in this study clearly showed the significant contribution of nitrogen in palm shell activated carbon (PSAC) impregnated using urea via MW irradiation for $\mathrm{H} 2 \mathrm{~S}$ adsorption. There are various factors that affecting the performance of adsorbent for $\mathrm{H} 2 \mathrm{~S}$ adsorption such as type of impregnation agent, surface chemistry and porosity. In fact, if the parameters of MW irradiation for NPSAC have been optimized, it will have a better chance to become a better adsorbent than NAOH-PSAC which is well known as a good adsorbent. Based on the H2S breakthrough capacity, the performance of both NAOH-PSAC and N-PSAC is $100 \%$ better than PSAC. This resulted from the development of physical and chemical characteristics of the adsorbents such as high surface area, smaller micropore size, and availability of oxygen and nitrogen surface functional groups. Thus, the impregnation of urea could be a benchmark to further study the nitrogen functionality in palm shell activated carbon. The unique features of N-PSAC show important improvement in the application of H2S adsorption. This study will provide great momentum to develop an effective method via MW irradiation in producing a great adsorbent. 


\section{Conflicts of Interest}

The authors declare that there is no conflict of interest regarding the publication of this paper.

\section{Acknowledgment}

The authors would like to acknowledge the financial supports from Ministry of Education Malaysia (MyBrain 15 Program), Knowledge Transfer Program (Grant No. 203/PJKIMIA/6750045), FELDA Palm Industries Sdn Bhd, and management funding from Universiti Teknologi MARA Cawangan Pulau Pinang.

\section{References}

[1] N. Hamzah, K. Tokimatsu, K. Yoshikawa, "Solid Fuel from Oil Palm Biomass Residues and Municipal Solid Waste by Hydrothermal Treatment for Electrical Power Generation in Malaysia: A Review" Sustainability, vol. 11, pp. 1060, 2019.

[2] S.Z.Y. Foong, M.F. Chong, D.K.S. Ng, "Strategies to Promote Biogas Generation and Utilisation from Palm Oil Mill Effluent" Process Integration and Optimization for Sustainability, vol. 5, pp. 175-191, 2021.

[3] R. Dimitrov, Z. Ivanov, P. Zlateva, V. Mihaylov, "Optimization of biogas composition in experimental studies" E3S Web of Conferences, vol. 112, pp. 02007, 2019.

[4] T.Y. Wu, M. Abdul Wahab, M.J. Jamaliah, A. Nurina, "Pollution control technologies for the treatment of palm oil mill effluent (POME) through end-of-pipe processes" Journal of Environmental Management, vol. 91, pp. 1467-1490, 2010.

[5] H.W. Ou, M.L. Fang, M.S. Chou, H.Y. Chang \& T.F. Shiao, "Long-term evaluation of activated carbon as an adsorbent for biogas desulfurization" Journal of the Air \& Waste Management Association, vol. 70, no. 6, pp. 641-648, 2020.

[6] G. Amvrosios, Georgiadis, N.D. Charisiou, M.A. Goula, "Removal of Hydrogen Sulfide From Various Industrial Gases: A Review of The Most Promising Adsorbing Materials" Catalysts, vol. 10, pp. 521, 2020.

[7] N.A. Rashidi, S. Yusup, "A review on recent technological advancement in the activated carbon production from oil palm wastes" Chemical Engineering Journal, vol. 314, pp. 277-290, 2017.

[8] Y. Li, Y. Lin, Z. Xu, B. Wang, T. Zhu, "Oxidation mechanisms of H2S by oxygen and oxygen-containing functional groups on activated carbon" Fuel Processing Technology, vol. 189, pp. 110-119, 2019.

[9] S. Wang, H. Nam, T.B. Gebreegziabher, H. Nam, "Adsorption of acetic acid and hydrogen sulfide using $\mathrm{NaOH}$ impregnated activated carbon for indoor air purification" Engineering Reports, vol. 2, pp. 12083, 2020.

[10] L.C. Lau, N.M. Nor, K.T. Lee, A.R. Mohamed, "Hydrogen sulfide removal using CeO2/NaOH/PSAC: Effect of preparation parameters" Journal of Environmental Chemical Engineering, vol. 6, no. 1, pp. 386-394, 2018.

[11] N.M. Nor, L.C. Lau, B.H. Hameed, S. Sethupathi, A.R. Mohamed, "Effect of Microwave Heating Variables on Nitrogen-Enriched Palm Shell Activated Carbon toward Efficient Hydrogen Sulfide Removal" Solid State Phenomena, vol. 280, pp. 315-322, 2018.

[12] C. Yang, S. Yang, H. Fan, Y. Wang, J. Shangguan, "Tuning the ZnO-activated carbon interaction through nitrogen modification for enhancing the H2S removal capacity" Journal of Colloid and Interface Science, vol. 555, pp. 548-557, 2019.

[13] X. Kan, X. Chen, W. Chen, et al. "Nitrogen-Decorated, Ordered Mesoporous Carbon Spheres as High Efficient Catalysts for Selective Capture and Oxidation of H2S" ACS Sustainable Chemical Engineering, vol. 7, pp. 7609-7618, 2019.

[14] R. Cherbański, "Regeneration of granular activated carbon loaded with toluene - Comparison of microwave and conductive heating at the same active powers" Chemical Engineering \& Processing: Process Intensification, vol. 123, pp. 148-157, 2018.

[15] X. Duan, C. Srinivasakannan, X. Wang, F. Wang, X. Liu, "Synthesis of activated carbon fibers from cotton by microwave induced H3PO4 activation" Journal of the Taiwan Institute of Chemical Engineers, vol. 70, pp. 374-381, 2017.

[16] J. Kazmierczak-Razna, B. Gralak-Podemska, P. Nowicki, R. Pietrzak, "The use of microwave radiation for obtaining activated carbons from sawdust and their potential application in removal of NO2 and H2S" Chemical Engineering Journal, vol. 269, pp. 352-358, 2015.

[17] C.J. Geankoplis, "Transport Processes and Separation Process Principles (Includes Unit Operations), $4^{\text {th }}$ Edition, Pearson, 2003.

[18] F. Adib, A. Bagreev, T.J. Bandosz, "Adsorption /oxidation of hydrogen sulfide on nitrogen-containing activated carbon" Langmuir, vol. 16, pp. 980-1986, 2000.

[19] A. Bagreev, T.J. Bandosz, "A role of sodium hydroxide in the process of hydrogen sulfide adsorption/oxidation on caustic-impregnated activated carbons" Industrial Engineering Chemical Resource, vol. 41, pp. 672-679, 2002. 
[20] M. Seredych, C. Portet, Y. Gogotsi, T.J. Bandosz, "Nitrogen modified carbide derived carbons as adsorbent of hydrogen sulfide" Journal of Colloid and Interface Science, vol. 330, pp. 60-66, 2009.

[21] S. Sumathi, S. Bhatia, K.T. Lee, A.R. Mohamed, "Selection of best impregnated palm shell activated carbon (PSAC) for simultaneous removal of SO2 and NOx" Journal of Hazardous Material, vol. 176, pp. 1093-1096, 2010. 